\title{
Synthesis of Polyenamines with Pendant Hydroxyl Groups by Ring-Opening Polyaddition of 5,5'-Oxalylbis(3,4- dihydro-2H-pyran) with Diamines
}

\author{
Mitsuru Ueda, Michio Funayama, and Yoshio ImaI \\ Department of Polymer Chemistry, Faculty of Engineering, \\ Yamagata University, Yonezawa 992, Japan.
}

(Received December 22, 1978)

\begin{abstract}
A new class of polyenamines with pendant hydroxyl groups was synthesized by the ring-opening polyaddition of 5,5'-oxalylbisi(3,4-dihydro- $2 H$-pyran) with diamines through vinylogous nucleophilic substitution. Solution polymerization carried out in alcoholic solvents such as $m$ cresol at room temperature afforded polymers having inherent viscosities of $0.1-0.27$ in quantitative yields. The hydroxyl-containing polyenamines were soluble in a limited number of solvents and had low softening temperatures, below $200^{\circ} \mathrm{C}$.

KEY WORDS Ring-Opening Polyaddition / 5,5'-Oxalylbis(3,4-dihydro2H-pyran) / Diamines / Hydroxyl-Containing Polyamides / Solubility / Softening Temperature /
\end{abstract}

Recently, it was reported from our laboratory that polyenamines were readily synthesized by the polycondensation of reactive bis(ethoxyvinyl ketone) and analogs with diamines under mild polymerization conditions. ${ }^{1,2}$ We proposed the term "vinylogous nucleophilic substitution polymerization" to account for this type of the polycondensation. The vinylogous nucleophilic substitution can be extended to aminolysis of cyclic vinyl ethers having an electron-withdrawing carbonyl group at the $\beta$ - position, leading to ring-opened adducts. We have found that 5,5'-oxalylbis(3,4-dihydro-2 $H$-pyran) (OBDP) met the important requirement of high reactivity for a reactive cyclic monomer which undergoes ring-opening polyaddition with diamines to yield polyenamines with pendant hydroxyl groups. This may provide the first example of a successful ring-opening polyaddition through vinylogous nucleophilic substitution polymerization.

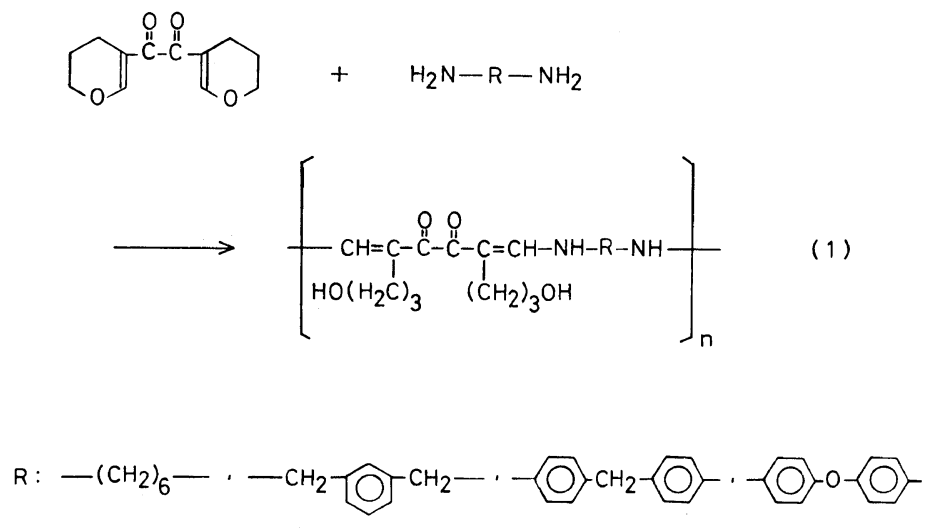




\section{EXPERIMENTAL}

\section{Materials}

5, 5'-Oxalylbis (3,4-dihydro-2H-pyran)

$(O B D P)$. This compound was prepared according to the procedure of Effenberger ${ }^{3}$ in $50 \%$ yield by the addition of oxalyl chloride to 3,4-dihydro- $2 \mathrm{H}$-pyran, followed by dehydrochlorination with triethylamine. Recrystallization from a mixture of petroleum ether and ethanol ( $4: 1$ by vol) afforded white needles, $\mathrm{mp}$ $115-116^{\circ} \mathrm{C}$ [lit. ${ }^{3} \mathrm{mp} 113^{\circ} \mathrm{C}$ ]. IR (KBr) $1600 \mathrm{~cm}^{-1}$ $(\mathrm{C}=\mathrm{O})$.

Diamines. Hexamethylenediamine (HMDA) and $m$-xylylenediamine (MXDA) were distilled in vacuo before use. Bis(4-aminophenyl)methane (MDA) and bis(4-aminophenyl) ether (ODA), both of which were supplied by Sumitomo Chemical Co., were purified by recrystallization from benzene and tetrahydrofuran, respectively.

Solvents and Reagents. $m$-Cresol was purified by vacuum distillation and stored over $4 . \AA$ molecular sieves. Benzyl alcohol, $p$-chloroaniline, and other reagents were obtained commercially and used as received.

\section{Model Reaction}

4,4'-Oxalylbis[5-(p-chlorophenylimino) 1-pentanol] (Ib). To a solution of $0.444 \mathrm{~g}(2 \mathrm{mmol})$ of OBDP in $5 \mathrm{~m} l$ of ethanol $0.510 \mathrm{~g}(4 \mathrm{mmol})$ of $p$-chloroaniline was added, and the solution was refluxed with stirring for 2 days. After the solution had been cooled in a refrigerator, the yellow precipitate which formed was collected by filtration and dried. The yield was $0.91 \mathrm{~g}(95 \%)$. Recrystallization from ethanol afforded small yellow crystals, $\mathrm{mp} 204^{\circ} \mathrm{C}$ (by DTA). IR $(\mathrm{KBr}) 3310(\mathrm{O}-\mathrm{H})$ and $1680 \mathrm{~cm}^{-1}(\mathrm{C}=\mathrm{O})$.

Anal. Calcd for $\mathrm{C}_{24} \mathrm{H}_{26} \mathrm{Cl}_{2} \mathrm{~N}_{2} \mathrm{O}_{4}: \mathrm{C}, 60.38 \% ; \mathrm{H}$, $5.49 \%$; N, 5.87\%. Found: C, 60.4\%; H, 5.7\%; N, $5.6 \%$.

\section{Polymerization}

Synthesis of Polyenamine III. To a solution of $0.582 \mathrm{~g}(5 \mathrm{mmol})$ of HMDA in $3.8 \mathrm{ml}$ of $m$-cresol $1.111 \mathrm{~g}(5 \mathrm{mmol})$ of OBDP was added, and the polymerization was continued with stirring at room temperature for 7 days. The resulting solution was poured into $300 \mathrm{~m} l$ of ether. The product was filtered off, washed thoroughly with ether, and dried. The yield was $1.68 \mathrm{~g}(99 \%)$. The inherent viscosity of the polymer in $m$-cresol was $0.25 \mathrm{~d} l / \mathrm{g}$, measured at a concentration of $0.5 \mathrm{~g} / \mathrm{d} l$ at $30^{\circ} \mathrm{C}$. IR $(\mathrm{KBr}) 3260$ $(\mathrm{O}-\mathrm{H}$ and $\mathrm{N}-\mathrm{H}), 1630(\mathrm{C}=\mathrm{O})$, and $1540 \mathrm{~cm}^{-1}$ $(\mathrm{N}-\mathrm{H})$.

Anal. Calcd for $\left(\mathrm{C}_{18} \mathrm{H}_{30} \mathrm{~N}_{2} \mathrm{O}_{4}\right)_{n}: \mathrm{C}, 63.88 \% ; \mathrm{H}$, $8.93 \%$; N, $8.28 \%$. Found: C, 63.6\%; H, 8.6\%; N, $8.3 \%$.

Synthesis of Polyenamine VI. A mixture of $0.501 \mathrm{~g}(2.5 \mathrm{mmol})$ of ODA and $0.556 \mathrm{~g}(2.5 \mathrm{mmol})$ of OBDP in $2.7 \mathrm{ml}$ of $m$-cresol was reacted at $80^{\circ} \mathrm{C}$ with stirring. After 4 days of polymerization, the polymer was isolated by precipitation with $300 \mathrm{ml}$ of ether. It weighed $0.97 \mathrm{~g}(97 \%)$, and its inherent viscosity was $0.13 \mathrm{~d} l / \mathrm{g}$. IR $(\mathrm{KBr}) 3340(\mathrm{O}-\mathrm{H})$ and $1960 \mathrm{~cm}^{-1}$ $(\mathrm{C}=\mathrm{O})$.

Anal. Calcd for $\left(\mathrm{C}_{24} \mathrm{H}_{26} \mathrm{~N}_{2} \mathrm{O}_{5}\right)_{n}: \mathrm{C}, 68.23 \%$; H, $6.20 \%$; N, $6.63 \%$. Found: C, $68.5 \%$; H, 5.7\%; N, $6.6 \%$.

\section{RESULTS AND DISCUSSION}

\section{Model Reaction}

The reactivity of 5-acyl-3,4-dihydro- $2 \mathrm{H}$-pyrans toward nucleophiles has been practically unknown to date. Therefore, the animolysis of the monomer OBDP was first investigated in detail to demonstrate the feasibility of this reaction for polymer formation and to obtain a model compound for use in polymer identification.

The reaction of OBDP with various amines was carried out in ethanol both at room temperature and at an elevated temperature. The reaction with $p$ chloroaniline yielded a readily crystallizable product having a carbonyl absorption at $1680 \mathrm{~cm}^{-1}$, believed to be due to the ring-opened adduct I (through path A), and not to the condensation product II (through path B) [eq 2].

Similarly, other amines such as aniline, benzylamine, and butylamine were found to react with OBDP to afford the corresponding oily ring-opened adducts.

This type of ring-opening reaction proceeds through a vinylogous nucleophilic additionelimination mechanism, as shown in eq 3 , analogous to that proposed for the polycondensation of bis(ethoxyvinyl ketones) with diamines. ${ }^{1,2}$

The infrared spectrum of the reaction product $\mathrm{I}$, given in Figure 1, exhibited strong bands at 3310 and $1680 \mathrm{~cm}^{-1}$ probably assignable to an $\mathrm{O}-\mathrm{H}$ stretching and a carbonyl absorption, respectively, and no clearly detectable band at around $1540 \mathrm{~cm}^{-1}$ due to 

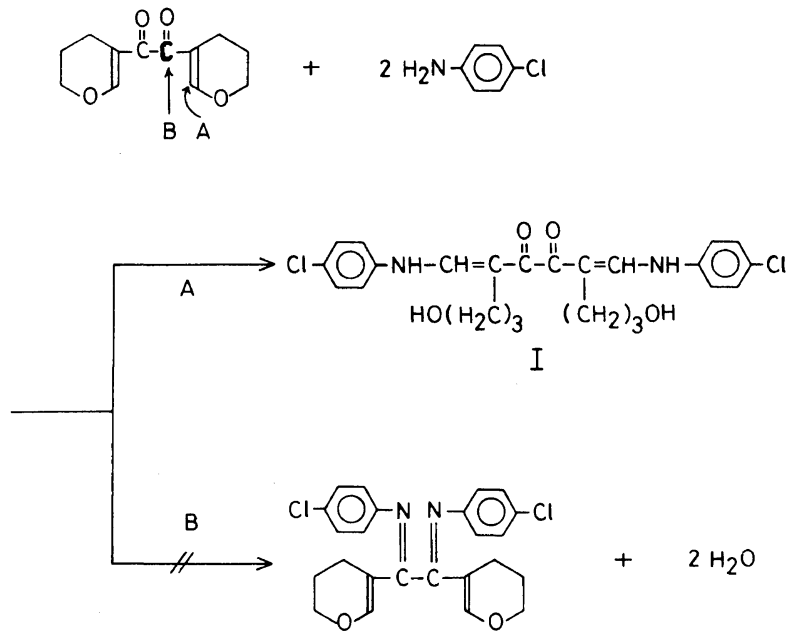

II

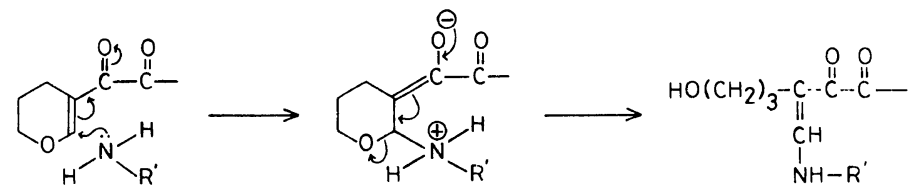

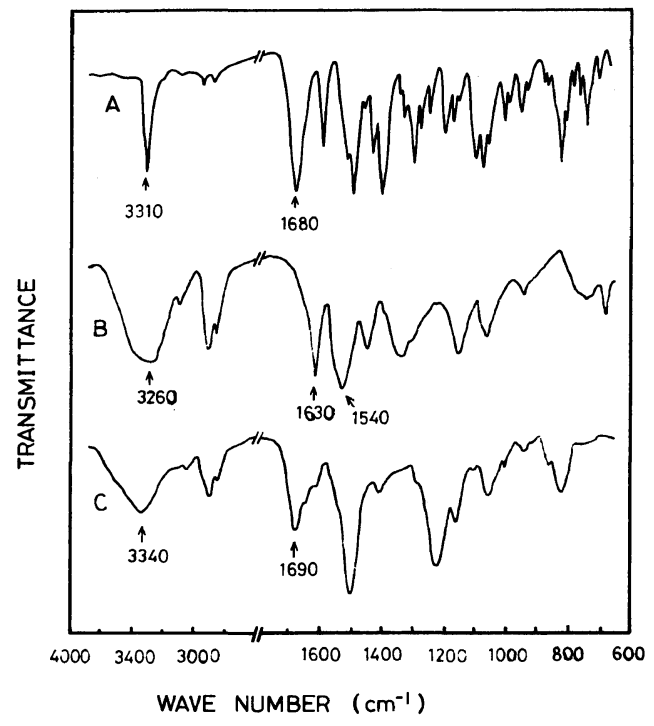

Figure 1. IR spectra of model compound and polyenamines: (A) the compound Ib; (B) the polymer III; (C) the polymer VI.

an $\mathrm{N}-\mathrm{H}$ deformation. Therefore, this compound is presumed to exist mainly in the imine form (Ib), rather than the enamine form (Ia) [eq 4].

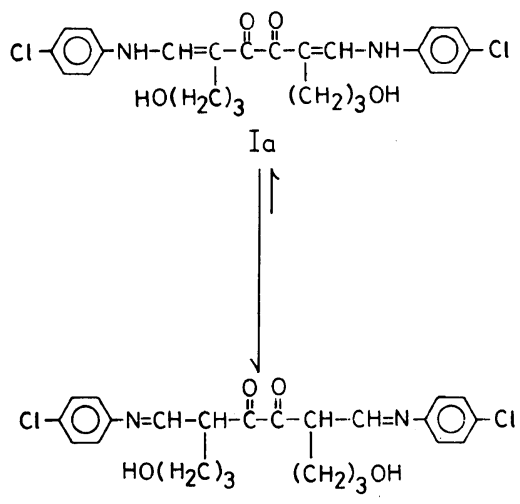

Ib

\section{Polymerization}

The high-yield model reaction of OBDP was extended to the ring-opening polyaddition with diamines, which proceeds according to eq 1 . The results of the polymerization are summarized in Table I.

It has been shown that alcoholic solvents were the best reaction media for the production of hydroxylcontaining polyamides from bis-4-butanolide and 
Table I. Conditions and results of the ring-opening polyaddition of the cyclic monomer OBDP with diamines

\begin{tabular}{|c|c|c|c|c|c|c|c|}
\hline \multirow[b]{2}{*}{ Polymer } & \multirow[b]{2}{*}{ Diamine } & \multicolumn{4}{|c|}{ Polymerization conditions $\mathrm{s}^{\mathrm{a}}$} & \multicolumn{2}{|c|}{ Polymer } \\
\hline & & Solvent ${ }^{\mathbf{b}}$ & $\begin{array}{c}\text { Concn, } \\
w^{\circ} \%\end{array}$ & $\begin{array}{c}\text { Temp } \\
{ }^{\circ} \mathrm{C}\end{array}$ & $\begin{array}{l}\text { Time, } \\
\text { day }\end{array}$ & $\begin{array}{l}\text { Yield, } \\
\%\end{array}$ & $\begin{array}{l}\eta_{\text {inh }}{ }^{\mathrm{c}} \\
\mathrm{d} l / \mathrm{g}\end{array}$ \\
\hline III & HMDA & $\mathrm{CR}$ & 17 & 20 & 1 & 84 & 0.15 \\
\hline III & HMDA & CR & 17 & 80 & 1 & 91 & 0.14 \\
\hline III & HMDA & $\mathrm{CR}$ & 30 & 20 & 7 & 99 & 0.25 \\
\hline III & HMDA & CR & 30 & 80 & 2 & 99 & 0.25 \\
\hline III & HMDA & CR & 40 & 20 & 7 & 99 & 0.24 \\
\hline III & HMDA & $\mathrm{BA}$ & 25 & 20 & 2 & 99 & 0.21 \\
\hline III & HMDA & CR-MA ${ }^{d}$ & 17 & 20 & 2 & 99 & 0.27 \\
\hline III & HMDA & CR-MA ${ }^{e}$ & 17 & 20 & 1 & 99 & 0.21 \\
\hline IV & MXDA & CR & 17 & 20 & 2 & 93 & 0.10 \\
\hline IV & MXDA & $\mathrm{CR}$ & 30 & 20 & 7 & 99 & 0.12 \\
\hline IV & MXDA & $\mathrm{BA}$ & 27 & 20 & 1 & 99 & $0.10^{f}$ \\
\hline $\mathrm{V}$ & MDA & $\mathrm{CR}$ & 30 & 50 & 4 & 92 & 0.12 \\
\hline VI & ODA & $\mathrm{CR}$ & 30 & 80 & 4 & 97 & 0.13 \\
\hline
\end{tabular}

a Polymerization was carried out with $2.5-5.0 \mathrm{mmol}$ of OBDP and of diamine.

b CR, $m$-cresol; BA, benzyl alcohol; MA, methanol.

c Measured at a concentration of $0.5 \mathrm{~g} / \mathrm{d} l$ in $m$-cresol at $30^{\circ} \mathrm{C}$.

d Mixture of methanol and $m$-cresol $(8: 2$ by wt).

e Mixture of methanol and $m$-cresol (9:1 by wt).

f Measured in benzyl alcohol.

diamines. ${ }^{4}$ In the present case, alcoholic solvents such as benzyl alcohol, $m$-cresol, and a mixture of $m$ cresol and methanol, were also used successfully for the preparation of hydroxyl-containing polyenamines, in which the polymerization proceeded in homogeneous solution. The polymerization temperature was found to have no effect, over a temperature range of $20-80^{\circ} \mathrm{C}$, on the inherent viscosity of the resulting polymers. The molecular weight tended to increase to some extent with increasing monomer concentration. Under these polymerization conditions, the ring-opened polymers having inherent viscosities in the range of $0.1-0.27 \mathrm{~d} l / g$ were obtained in almost quantitative yields. The formation of the polymers with relatively low molecular weight may be attributable to the lower reactivity of OBDP as compared to the reactivity of 1,6-diethoxy-1,5hexadiene-3,4-dione having an open-chain structure. $^{2}$

The formation of the polymers was confirmed by means of IR spectroscopy and elemental analyses. Figure 1 shows the IR spectra of the polymers III and VI. These spectra suggest that the polyenamines derived from aliphatic diamines (HMDA and
MXDA) differ in structure from the polymers obtained from aromatic diamines (MDA and ODA). The spectra of the aromatic polymers (V and VI) exhibited an $\mathrm{O}-\mathrm{H}$ stretching band at $3340 \mathrm{~cm}^{-1}$ and a strong carbonyl stretching at $1690 \mathrm{~cm}^{-1}$, which compares favorably with that of the model compound I. Therefore, these polymers appear to exist predominantly in the imine form similar to the structure Ib. On the other hand, the spectra of the aliphatic polymers (III and IV) showed an overlapped $\mathrm{O}-\mathrm{H}$ and $\mathrm{N}-\mathrm{H}$ stretching band near 3260 $\mathrm{cm}^{-1}$, a sharp carbonyl stretching at $1630 \mathrm{~cm}^{-1}$, and a strong $\mathrm{N}-\mathrm{H}$ deformation at $1540 \mathrm{~cm}^{-1}$. This probably indicates that the aliphatic polymers exist mainly in the enamine form.

\section{Properties of Polymers}

These hydroxyl-containing polyenamines were soluble in $m$-cresol, benzyl alcohol, and 1-methyl-2pyrrolidone, and practically insoluble in other common organic solvents. They dissolved in acidic media such as concd.sulfuric, dichloroacetic, and formic acids, with degradation of the polymer main chain, analogous to other polyenamines. ${ }^{1,2}$ 


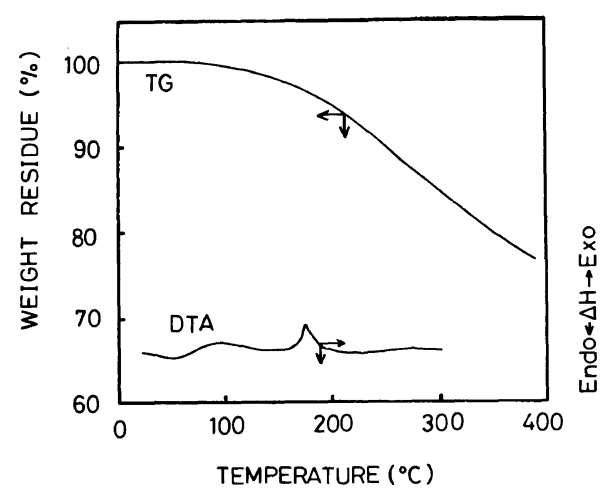

Figure 2. DTA and TG thermograms for the polyenamine V: DTA in air at a heating rate of $10^{\circ} \mathrm{C} / \mathrm{min}$, and $\mathrm{TG}$ in nitrogen at a heating rate of $5^{\circ} \mathrm{C} / \mathrm{min}$.

All of the polymers softened at temperatures below $200^{\circ} \mathrm{C}$, and began to decompose above the softening temperature, as observed by DTA and TG (Figure 2). The thermal behavior data are summarized in Table II.

Acknowledgment. The authors are indebted to
Table II. Thermal behavior data of the polyenamines

\begin{tabular}{lrcc}
\hline Polymer $\begin{array}{c}\text { Softening } \\
\text { temp, } \\
{ }^{\circ} \mathrm{C}^{\mathrm{a}}\end{array}$ & $\begin{array}{c}\text { Main } \\
\text { exothermic } \\
\text { peak temp, }{ }^{\circ} \mathrm{C}^{\mathrm{b}}\end{array}$ & $\begin{array}{c}\text { Decomposition } \\
\text { temp, }{ }^{\circ} \mathrm{C}^{\mathrm{c}}\end{array}$ \\
\hline III & $67-104$ & 147 & 210 \\
IV & $133-141$ & 160 & 240 \\
V & $152-159$ & 174 & 245 \\
VI & $180-197$ & - & 245 \\
\hline a Observed visually on a hot-stage microscope. \\
b Determined by DTA in air at a heating rate of \\
$10^{\circ} \mathrm{C} /$ min. \\
c A $10 \%$ weight-loss temperature observed by $\mathrm{TG}$ in \\
nitrogen at a heating rate of $5^{\circ} \mathrm{C} /$ min.
\end{tabular}

Mr. Sadao Kato for the performance of the elemental analyses.

\section{REFERENCES}

1. M. Ueda, K. Kino, T. Hirono, and Y. Imai, J. Polym. Sci., Polym. Chem. Ed., 14, 931 (1976).

2. M. Ueda, K. Otaira, and Y. Imai, J. Polym. Sci., Polym. Chem. Ed., 16, 2809 (1978).

3. F. Effenberger, Chem. Ber., 98, 2260 (1965).

4. M. Ueda, M. Yabuuchi, and Y. Imai, J. Polym. Sci., Polym. Chem. Ed., 15, 323 (1977). 